\title{
Progression of pulmonary hyperinflation and trapped gas associated with genetic and environmental factors in children with cystic fibrosis
}

\author{
Richard Kraemer*1,2, David N Baldwin², Roland A Ammann ${ }^{1}$, Urs Frey ${ }^{1,2}$ and \\ Sabina Gallati ${ }^{1,3}$
}

Address: ${ }^{1}$ Department of Paediatrics, University of Berne, Inselspital CH-3010 Berne, Switzerland., ${ }^{2}$ Division of Pediatric Respiratory Medicine, Department of Pediatrics, University of Berne, Inselspital, CH-3010 Berne, Switzerland. and ${ }^{3}$ Division of Human Genetics, Department of Pediatrics, University of Berne,, Inselspital, CH-3010 Berne, Switzerland.

Email: Richard Kraemer* - richard.kraemer@insel.ch; David N Baldwin - dn_baldwin@hotmail.com;

Roland A Ammann - roland.ammann@insel.ch; Urs Frey - urs.frey@insel.ch; Sabina Gallati - sabina.gallati@insel.ch

* Corresponding author

Published: 30 November 2006

Respiratory Research 2006, 7:138 doi:10.1 186/1465-992I-7-138
Received: 07 August 2006

Accepted: 30 November 2006

This article is available from: http://respiratory-research.com/content/7////38

(C) 2006 Kraemer et al; licensee BioMed Central Ltd.

This is an Open Access article distributed under the terms of the Creative Commons Attribution License (http://creativecommons.org/licenses/by/2.0), which permits unrestricted use, distribution, and reproduction in any medium, provided the original work is properly cited.

\begin{abstract}
Background: Functional deterioration in cystic fibrosis (CF) may be reflected by increasing bronchial obstruction and, as recently shown, by ventilation inhomogeneities. This study investigated which physiological factors (airway obstruction, ventilation inhomogeneities, pulmonary hyperinflation, development of trapped gas) best express the decline in lung function, and what role specific CFTR genotypes and different types of bronchial infection may have upon this process.

Methods: Serial annual lung function tests, performed in 152 children (77 males; 75 females) with $\mathrm{CF}$ (age range: 6-18 y) provided data pertaining to functional residual capacity $\left(F R C_{\text {pleth }}, \mathrm{FRC}_{\mathrm{MBNW}}\right)$, volume of trapped gas $\left(V_{T G}\right)$, effective specific airway resistance $\left(s R_{\text {eff }}\right)$, lung clearance index $(L C l)$, and forced expiratory indices ( $F V C, \mathrm{FEV}_{1}, \mathrm{FEF}_{50}$ ).

Results: All lung function parameters showed progression with age. Pulmonary hyperinflation $\left(\mathrm{FRC}_{\text {pleth }}>2 \mathrm{SDS}\right)$ was already present in $39 \%$ of patients at age 6-8 yrs, increasing to $67 \%$ at age 18 yrs. The proportion of patients with $\mathrm{V}_{\mathrm{TG}}>2 \mathrm{SDS}$ increased from $15 \%$ to $54 \%$ during this period. Children with severe pulmonary hyperinflation and trapped gas at age 6-8 yrs showed the most pronounced disease progression over time. Age related tracking of lung function parameters commences early in life, and is significantly influenced by specific CFTR genotypes. The group with chronic $P$. aeruginosa infection demonstrated most rapid progression in all lung function parameters, whilst those with chronic $S$. aureus infection had the slowest rate of progression. $\mathrm{LCl}$, measured as an index of ventilation inhomogeneities was the most sensitive discriminator between the 3 types of infection examined $(p<0.000 I)$.

Conclusion: The relationships between lung function indices, CFTR genotypes and infective organisms observed in this study suggest that measurement of other lung function parameters, in addition to spirometry alone, may provide important information about disease progression in CF.
\end{abstract}




\section{Background}

Cystic fibrosis (CF) is the most common life-shortening genetic disease among Caucasians, being caused by mutations of the cystic fibrosis transmembrane conductance regulator (CFTR) gene [1]. Dysregulation of epithelial chloride channels results in dehydration of the luminal surface of exocrine cells, increased mucus viscosity and altered mucociliary clearance. The occurrence of these changes most likely follows periciliary liquid layer depletion and together are responsible for the CF phenotype [25]. Recent data have linked the abnormal ion transport properties of CF airway epithelia to depleted airway surface liquid volume, reflecting the combined defects of accelerated $\mathrm{Na}^{+}$transport and the failure to secrete $\mathrm{Cl}^{-}$. Depletion of a specific compartment of the airway surface liquid, i.e. the periciliary fluid, appears to abrogate both cilia-dependent and cough clearance $[4,6]$. Mucus clearance is a major component of the lung's innate defense mechanism. The efficiency of mucus clearance reflects in part the volume of airway surface liquid (ASL) on airway surfaces. The ASL is comprised of a periciliary liquid layer (PCL), which lubricates the cell surface, and a mucus layer, which traps airborne particles and pathogens [7]. Cystic fibrosis airways exhibit $\mathrm{Na}^{+}$hyperabsorption and $\mathrm{Cl}^{-}$hyposecretion, which leads to ASL volume depletion, mucus stasis, and mucus plugging. These mucus plugs are the site of persistent bacterial infections that lead to a massive neutrophil infux and raised immune responses that promote airway remodeling [8]. Regulation of ASL volume is poorly understood [9], although Tarran et al. recently showed that CF airway epithelia lack CFTRdependent $\mathrm{Cl}^{-}$secretion and exhibit $\mathrm{Na}^{+}$hyperabsorption, leaving CF cultures only partially able to adjust ASL volume $[9,10]$. Bacterial colonization, infection, and chronic pulmonary inflammation develop subsequently. Pulmonary complications account for most of the morbidity and mortality in CF patients, and the majority of patients with CF die from respiratory failure due to endobronchial infection and neutrophil-dominated inflammation $[11,12]$. Advances in the care of patients with CF have improved survival, and as a result, patients with the disease now often live beyond the third decade [13]. The heterogeneous course of disease progression observed in CF remains incompletely explained and most likely reflects the influence of multiple, interrelated factors. These may include differences in CFTR mutation and presence of infective organisms within the respiratory tract $[14,15]$.

Previous studies in patients with CF have demonstrated the presence of ventilation inhomogeneities [16,17], pulmonary hyperinflation [18-21] and gas trapping [22] as early as during the first years of life [17-19], and these may progress during childhood $[16,20]$. Only few observational population-based studies [23-26] have specifically evaluated progression of lung function characteristics such as airway obstruction, ventilation inhomogeneities, pulmonary hyperinflation, and development of trapped gas over time. We have previously reported observations that inequalities in ventilation occur significantly earlier in the course of lung function decline than other functional characteristics [16]. Here we hypothesize that functional consequences of lung disease in CF extend beyond simple bronchial obstruction, and should be examined in terms of alveolar volume, including gas trapping, as well as alveolar ventilation.

In the current study we investigated $(i)$ whether or not pulmonary hyperinflation and/or trapped gas represent further indicators of functional deterioration that should be monitored during childhood. Moreover, we attempted (ii) to define the role of specific CFTR genotypes and the influence of PA infection upon rates of disease progression. Finally, we intended (iii) to demonstrate whether or not those young children in whom respiratory dysfunction occurs earliest and with greatest severity, are more likely to follow a more rapid decline in pulmonary function, consistent with the concept of functional tracking over time. Progressive functional deterioration of this type has been previously reported in several chronic respiratory diseases including bronchial asthma $[27,28]$ chronic lung disease of infancy [29] and cystic fibrosis $[16,25,26,30]$.

\section{Study population and methods Bernese Cystic Fibrosis Patient Data Registry}

This prospective registry was initiated in 1978 as an extension of the American Cystic Fibrosis Patient Registry founded by Warwick in 1966 [31], and comprises systematic clinical and lung function data obtained from CF patients reviewed as inpatients and outpatients over a time span of 28 years. This comprehensive source provided data for the observational cohort study which were reviewed according to the following inclusion criteria: (i) CF diagnosis based on the presence of characteristic phenotypic features [32,33], (ii) confirmed by a duplicate quantitative pilocarpine iontophoresis sweat test measuring both $\mathrm{Na}$ and $\mathrm{Cl}$ values $>60 \mathrm{mEq} / \mathrm{L}$ as well as by (iii) genotype identification using extended mutation screening of both alleles [34,35], and (iv) complete documentation of a minimum of 4 lung function tests performed annually between age 6-18 y. The study protocol was approved by the Departmental Ethics Committee of the University Children's Hospital and by the Government Ethics Committee of the State of Berne, Switzerland. Parts of the lung function data from this cohort have been reported previously [16].

\section{Pulmonary Function Measurements}

Spirometry and flow volume curves were obtained by whole body plethysmography using a volume-constant, 
pressure-variable plethysmograph with air bag body temperature and pressure saturated (BTPS) compensation unit (BodyScreen, Jaeger Würzburg, Germany) until December 4, 1993. Thereafter, the MasterLab plethysmograph was employed (MasterLab, Jaeger Würzburg, Germany). This instrument uses electronic BTPScompensation. Children were requested to breathe at coached normal frequency during shutter closure (no panting) for measurements of functional residual capacity $\left(\mathrm{FRC}_{\text {pleth }}\right)$. Prior to plethysmographic measurements, resting end-expiratory lung volume ( $\left.\mathrm{FRC}_{\mathrm{MBNW}}\right)$ and quantification of ventilation inhomogeneities (LCI) was determined by open-circuit multibreath nitrogen washout (MBNW) technique [36] using the Pediatric Pulmonary Unit (SensorMedics 2200, Yorba Linda, Ca, USA). This procedure enabled longitudinal assessment of the following parameters: (i) FRC $_{\text {pleth }}$ measured by whole-body plethysmography, (ii) $\mathrm{FRC}_{\mathrm{MBNW}}$ measured by MBNW technique, combining both measurements to calculate (iii) an index of the volume of trapped gas $\left(\mathrm{V}_{\mathrm{TG}}=\mathrm{FRC}_{\mathrm{pleth}}\right.$ $\left.-\mathrm{FRC}_{\mathrm{MBNW}}\right)$ [37] and (iv) effective specific airway resistance $\left(s R_{\text {eff }}\right)$. Following a short rest period, indices of forced expiratory air flow limitation including $(v)$ forced vital capacity (FVC), ( $v i$ ) forced expired volume in one second $\left(\mathrm{FEV}_{1}\right)$ and (vii) maximal expired volume at 50 percent of FVC $\left(\mathrm{FEF}_{50}\right)$ were calculated from maximal expiratory flow volume curves. All measurements were stored for offline analysis and the 3-5 technically most satisfactory maneuvers were chosen for analysis using a computer system adapted for children (MasterLab, Jaeger Würzburg, Germany). With the exception of LCI, all values were expressed as a standard deviation score (SDS) based on gender- and age-specific regression equations [38-40]. Interpretation of LCI data required a z-transformation of log-transformed gender-specific data obtained in healthy subjects [38]. Technical details are given elsewhere $[16,41]$.

We have recently identified lung clearance index (LCI) obtained by multiple breath nitrogen washout (MBNW) technique [16], followed by $\mathrm{MEF}_{50}$ and $\mathrm{FRC}_{\text {pleth }}$ as the strongest indicators of disease progression. Furthermore, LCI was observed to reflect progressive deterioration in lung function earlier in life than alterations occurring in $\mathrm{FEV}_{1}$. Assessment of the degree of airway obstruction alone may therefore be inadequate for following progression of lung disease in CF. For example, in patients with end-stage CF lung disease, pulmonary hyperinflation is correlated with gas exchange characteristics [42]. Physiologically, at least five potential mechanisms of functional deterioration exist that may alter gas exchange, including: (a) progression of pulmonary hyperinflation, represented by $\mathrm{FRC}_{\text {pleth' }}(b)$ progression of ventilation inhomogeneities (LCI), (c) development of trapped gas $\left(\mathrm{V}_{\mathrm{TG}}\right),(d)$ air- way narrowing $\left(\mathrm{sR}_{\mathrm{eff}}\right)$ and $(e)$ small airway disease $\left(\mathrm{FEV}_{1}\right.$ and $\left.\mathrm{FEF}_{50}\right)$.

Therefore, progression of disease as quantified by the tracking of lung function decline was evaluated by stratification of patients into 4 subgroups according to the following criteria:

1) Group FN included 24 patients with functionally nor-

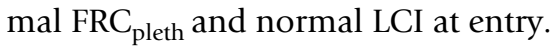

2) Group VIH comprised 71 patients in whom only ventilation inhomogeneities were present (normal $\mathrm{FRC}_{\text {plethi }}$; LCI > 2SDS; no trapped gas).

3) Group PH included 29 patients with pulmonary hyperinflation $\left(\mathrm{FRC}_{\text {pleth }}>2 \mathrm{SDS}\right)$ in the absence of trapped gas. Each of these children also had ventilation inhomogeneities present (LCI > 2SDS).

4) Group PH\&TG comprised 28 patients with pulmonary hyperinflation $\left(\mathrm{FRC}_{\text {pleth }}>2 \mathrm{SDS}\right)$, trapped gas $\left(\mathrm{V}_{\mathrm{TG}}>\right.$ 2SDS) and elevated LCI.

\section{Genotype analysis}

Genomic DNA was extracted from EDTA blood samples using the QIAamp Maxi Kit (Qiagen) according to the manufacturer's recommendations and quantified by spectrophotometry. In addition, a non-invasive method of buccal cell brushing [43] was used to obtain DNA from premature infants, recipients of previous blood transfusions and infants with meconium ileus. Mutation screening of the entire coding sequences of the CFTR gene (including the 27 exons and exon/intron boundaries, intron 11 and 19, as well as the promoter region) was performed for each patient using a well-established single strand conformation polymorphism/heteroduplex (SSCP/HD) analysis. This was followed by direct sequencing of the variants, thus permitting rapid and sensitive detection of $97-98 \%$ of known and novel (newly identified) CF mutations, as previously described [34,44,45].

\section{Microbiology}

Sputum and throat swabs were obtained at each follow-up visit and cultured for various bacterial species including $H$. influenzae, S. aureus and P. aeruginosa [46]. Sampling, transport, culture and identification of strains from respiratory secretions were performed according to standard procedures [46]. Sputum specimens were processed by the Institute of Microbiology, University of Berne, where they were inoculated on blood, chocolate and MacConkey agars [47]. Strains of P. aeruginosa, Staphylococcus aureus and Haemophilus influenzae were tested for antibiotic susceptibility by the Kirby-Bauer paper disk method. 


\section{Data computation and statistical evaluation}

In order to present individual values of lung function numerically and independent of gender, age and growth status, all lung function data were expressed as standard deviation score (SDS). The value obtained by z-transformation [48] indicates the number of standard deviations (SD) a CF-patient deviates from the gender- and age-specific regression equations for healthy subjects reported previously [38-40]. Repeated measurements of lung function data were first calculated as mean \pm SEM values per year over age for synoptical presentation. Linear mixedeffect model (LMM) analysis was used to assess the relationship between each lung function parameter and age [16,49-52], (i) to obtain reliable estimates of individual changes over time of an outcome, and hence, to examine progression of each lung function parameter, and (ii) to study the role of potentially associated factors such as specific CFTR genotypes or bacterial colonization over the age range of $6-8$ to 18 years. This technique is suited to analysis of the association between time and covariates from irregularly spaced serial data from individuals (i.e. repeated measurements), without being affected by missing data [49-52]. The various lung function parameters were modelled with age at observation as fixed effect, and a patient-specific intercept as random effect. A $t$-test assuming unequal variances was then performed to determine if regression slopes of the different lung function parameters in the whole sample differed from zero, and to test for differences of the regression slopes between groups. Holm's modification of the Bonferroni correction for multiple comparison was applied. The $p$-values significant at the 0.05 level after this correction are marked with an asterisk in the text and tables. Results with a significance level of $\mathrm{p}<0.05$ were considered statistically significant. Prism software (version 4.0, GraphPad Software, Inc., San Diego, USA) was used for graphical, and SPSS (version 11, SPSS Inc., Chicago, USA) for statistical analysis.

\section{Results}

\section{Characteristics of the study population}

The current Bernese Cystic Fibrosis Patient Data Registry contains data from a total of 190 CF patients who have been followed over the last 28 years. From this collective $152(76.8 \%)$ fulfilled the inclusion criteria defined for the present study (Table 1). Fifteen patients have not yet reached the age of 6 years, and in 23 CF patients less than 4 annual lung function tests were available. Gender was approximately equally distributed. Within these $152 \mathrm{CF}$ patients a total of 1460 lung function tests were performed, representing a median (range) of 10 (4 - 15) lung function tests per child, or $83(29-116)$ lung function tests per year.
According to the frequencies in our population-specific CFTR genotype distribution the patients were stratified into 4 CFTR-specific groups (Table 1). Group 1 consisted of those with a homozygous $\Delta$ F508 mutation $(\Delta F 508(2)$ : $\mathrm{n}=86,56.6 \%)$. Group 2 included compound heterozygotes for the second most common mutation found in Switzerland, 3905insT and $\Delta \mathrm{F} 508$ (3905insT/ $\Delta \mathrm{F}: \mathrm{n}=13$, $8.6 \%$ ). Compound heterozygotes for the nonsense mutation $\mathrm{R} 553 \mathrm{X}$ and $\Delta \mathrm{F} 508$ constituted group 3 with the third most common genotype (R553X/ $\Delta \mathrm{F}: \mathrm{n}=106.6 \%)$, whereas the fourth group comprised 43 miscellaneous genotypes $(28.3 \%)$.

Stratification into different types of bronchial infection (Table 1) was performed by defining those free of any colonization ( $n=6,3.9 \%)$, those presenting with intermittent colonization with one or more positive cultures of either $H$. influenzae, S. aureus, or St. maltofilia ( $\mathrm{n}=34$, $22.4 \%$ ), those chronically infected with S.aureus ( $\mathrm{n}=19$, $12.5 \%)$, those chronically infected by $P$. aeruginosa $(\mathrm{n}=$ $36,23.7 \%$ ), and those culture positive for both $P$. aeruginosa and $S$. aureus $(\mathrm{n}=57,37.5 \%)$.

\section{Progression of lung function over time}

Figure 1 shows mean annual changes of static lung volume (panel A), changes in LCI, and $\mathrm{sR}_{\text {eff }}$ (panel B) as estimates of intrapulmonary gas distribution and airway narrowing, and changes in flow volume curve derived indexes (panel $\mathrm{C}$ ) in relation to patient age over an age range of 6 to 18 years. Values are presented as mean $\mathrm{Z}$ scores, equal to SDS \pm SEM. $\mathrm{FRC}_{\text {pleth' }}$ obtained by whole body-plethysmography, increased from $1.43 \pm 0.15$ SDS at age $6 \mathrm{y}$ to $3.05 \pm 0.22$ SDS at the age of $18 \mathrm{y}$. Thus, while $38.7 \%$ of patients aged 6 to 8 yrs were found to have pulmonary hyperinflation (SDS-value $>2$ ), the proportion of children continued to increase, with $67.0 \%$ observed to have hyperinflation at $18 \mathrm{y}$. Trapped gas volume also increased from $0.62 \pm 0.16$ at 6 y to $2.65 \pm 0.22$ at $18 \mathrm{y}$. The proportion of patients with $\mathrm{V}_{\mathrm{TG}}$ increased from $15 \%$ to $54 \%$ during this period. In contrast, $\mathrm{FRC}_{\mathrm{MBNW}}$ values obtained by multibreath washout decreased during this period from $0.98 \pm 0.15$ SDS at age $6 y$ to $0.41 \pm 0,16$ at $18 \mathrm{y}$.

Table 2 demonstrates the age related progression of all lung function parameters with the exception of FVC as assessed by LMM analysis and expressed as the changes occurring in mean regression slope for each index. Rates of progression were most significant for $\mathrm{FEF}_{50}$ (slope: $0.505, p<0.0001), \mathrm{sR}_{\text {eff }}$ (slope: $0.381, p<0.001$ ), and LCI (slope: $0.281, p<0.001$ ). Less pronounced progression was also identified for pulmonary hyperinflation (FRCpleth: slope: $0.154, p<0.0001)$,) and trapped gas $\left(\mathrm{V}_{\mathrm{TG}}\right.$ : slope: $0.185, p<0.0001)$. 
Table I: Patient cohort, data base characteristics, distribution of CFTR mutations, and stratification into different types of bronchial infection in study patients with cystic fibrosis

Patient (from database*)

Follow-up statistic (from database*)

\begin{tabular}{l}
\hline \\
\hline all \\
- males \\
- females \\
\hline \multicolumn{1}{c}{ CFTR mutation stratification } \\
\hline \\
\hline $\begin{array}{l}\text { F508(2) } \\
\text { R505ins } / \Delta \mathrm{F} \\
\text { Miscellaneous }\end{array}$
\end{tabular}

$\%$ number of tests

age ranges covered

\section{2 total}

$77 \quad 50.7$ per child

56.6 Miscellaneous: numbers in brackets

$3 \quad 8.6 \Delta \mathrm{F} 508$ and I7I7-IG>A(4), WI282X(4), 2347delG(3), G524X(2), Q525X(2), NI303K(2), 62 I+IG>T(I)

$6.62176 \mathrm{ins} C(\mathrm{I}), 394 \mathrm{delTT}(\mathrm{I}), 4005+\mathrm{IG}-\mathrm{A}(\mathrm{I}) .420 \mathrm{del} 9(\mathrm{I})$, E585X(I), GI26D(I), G85E(I), R347P(I), 1078delT(I):

Miscellaneous

$4328.3 \quad 3905 \mathrm{insT}$ and I7I7-IG $>A(I), K 710 X(1)$, MI IOIK(I), Q39X(I), P5L(I), R553X(I);

R553X andR553X(I);

G542X and T5(3), G542X(I):

NI303K and2347delG(), 2789+5G>A(I);

I I99delG andR560S(I)

\begin{tabular}{ll}
$\begin{array}{c}\text { Stratification into different types } \\
\text { of infection }\end{array}$ & \\
\hline & $n \quad \%$
\end{tabular}

\begin{tabular}{lccl}
\hline free from any & 6 & 3.9 & \\
intermittend with various* & 34 & 22.4 & $*$ H. influenzae, S. aureus, St. maltofilia \\
S. aureus & 19 & 12.5 & \\
P. aeruginosa & 36 & 23.7 & \\
P. aeruginosa combined S. aureus & 57 & 37.5 &
\end{tabular}

*Actual number of patients in database: 198

$\infty \quad$ Number of patient under age of 6 years: 13

Number of patients with follow-up data less than 4 annual lung function tests: 23 

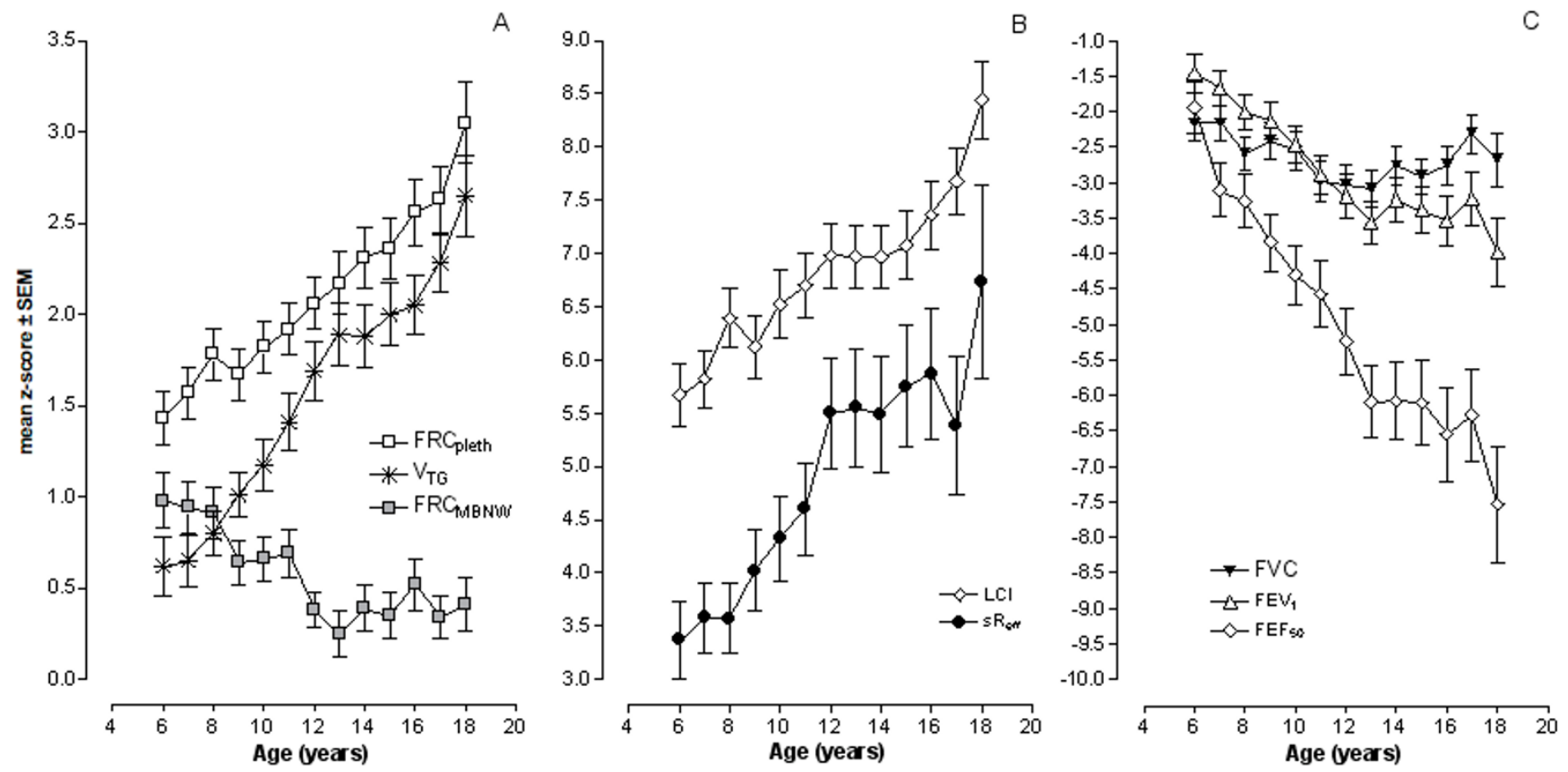

Figure I

Progression of lung function with age. A) Changes assessed by repeated measurements of plethysmographic functional residual capacity $\left(F R C_{\text {pleth }}\right)$, functional residual capacity obtained by the multibreath nitrogen washout $\left(F R C_{M B N W}\right)$, and volume of trapped gas $\left(\mathrm{V}_{\mathrm{TG}}\right)$. $\mathrm{V}_{\mathrm{TG}}$ was calculated as the difference between $F R C_{\text {pleth }}$ and $F R C_{M B N W}$. B) Changes of lung clearance index $(\mathrm{LCl})$ as a measure of ventilation inhomogeneities and effective specific airway resistance $\left(s R_{\text {eff }}\right.$ ), as measure of airway narrowing. C) Changes of forced vital capacity (FVC), forced expired volume in one second (FEVI) and maximal expired flow at $50 \%$ $\mathrm{FVC}\left(\mathrm{FEF}_{50}\right)$ in relation to age. All parameters expressed as z-scores.

Table 2: Progression with age (slope of regression) assessed by linear mixed-effect model analysis (LMM) in I52 patients with cystic fibrosis, evaluated over an age-range of 6 to 18 years.

\begin{tabular}{|c|c|c|c|c|c|}
\hline & \multirow{2}{*}{$\begin{array}{l}\text { Progression with } \\
\text { age of lung function }\end{array}$} & \multicolumn{2}{|c|}{$95 \%$ confidence interval } & \multicolumn{2}{|c|}{ Age as fixed effect } \\
\hline & & lower & upper & F-value & Significance \\
\hline FRC $_{\text {pleth }}$ & 0.142 & 0.126 & 0.158 & 298.3 & 0.0001 \\
\hline$F_{\text {RBNW }}$ & -0.062 & -0.081 & -0.043 & 42.1 & 0.001 \\
\hline LCI & 0.240 & 0.204 & 0.276 & 174.4 & 0.0001 \\
\hline $\mathbf{v}_{\mathrm{TG}}$ & 0.180 & 0.160 & 0.200 & 320.9 & 0.0001 \\
\hline $\mathbf{s} \mathbf{R}_{\text {eff }}$ & 0.373 & 0.319 & 0.427 & 182.1 & 0.0001 \\
\hline FVC & 0.005 & -0.023 & 0.033 & 0.1 & n.s. \\
\hline FEV $_{1}$ & -0.177 & -0.206 & -0.148 & 139.6 & 0.0001 \\
\hline FEF $_{50}$ & -0.474 & -0.527 & -0.420 & 304.0 & 0.0001 \\
\hline
\end{tabular}


Effect of early pulmonary hyperinflation and gas trapping on later functional outcome

Figure 2 shows the progression of $F_{R C} C_{\text {pleth }}(A)$ and $V_{T G}(B)$ over time for each of the 4 functional groups, stratified according to age at entry (age 6 to 8 yrs). Children initially presenting with both pulmonary hyperinflation and trapped gas (group PH\&TG) demonstrated highest values for both $\mathrm{FRC}_{\text {pleth }}$ and $\mathrm{V}_{\mathrm{TG}}$. These patients also showed consistently higher degrees of hyperinflation over time in comparison to those in whom pulmonary hyperinflation occurred in the absence of trapped gases (group PH). Furthermore, age related progression of disease was associated with development of similar degrees of gas trapping between functional groups as evidenced by the similar slopes of these parameters in Figure 2. Occurrence of ventilation inhomogeneities in the absence of hyperinflation was associated with both progression of both $\mathrm{FRC}_{\text {pleth }}$ and trapped gas. Presence of initially normal lung function or early ventilation inhomogeneities still resulted in progressive elevation of both $\mathrm{FRC}_{\text {pleth }}$ and $\mathrm{V}_{\mathrm{TG}}$ over time. However, CF patients with early severe functional deficits (groups PH and PH\&TG) showed consistent differences $(\mathrm{p}<0.001)$ from the other groups, which persisted throughout the entire duration of the study (i.e. demonstrated tracking).

\section{Relationship between lung function parameters and CFTR genotype}

Associations between lung function and CFTR genotypes, progression of changes in specific functional indexes within CFTR genotype groups and comparisons between functional groups are given in Table 3. Potential associations were assessed by LMM analysis incorporating data from the 3 specific mutation groups (i.e. excluding the group comprising miscellaneous genotypes). Age and the 3 most frequent CFTR groups were taken as fixed effects and the patient-specific intercept as random effect. The most significant age related progression was identified within the 3905insT/ $\Delta \mathrm{F}$ mutation group for $\mathrm{FEF}_{50}$ (slope: -0.738) and $\mathrm{sR}_{\text {eff }}$ (slope 0.549; panel A). The effect of mutation group was assessed by analyzing the position of the intercept through the ordinate. This value was found
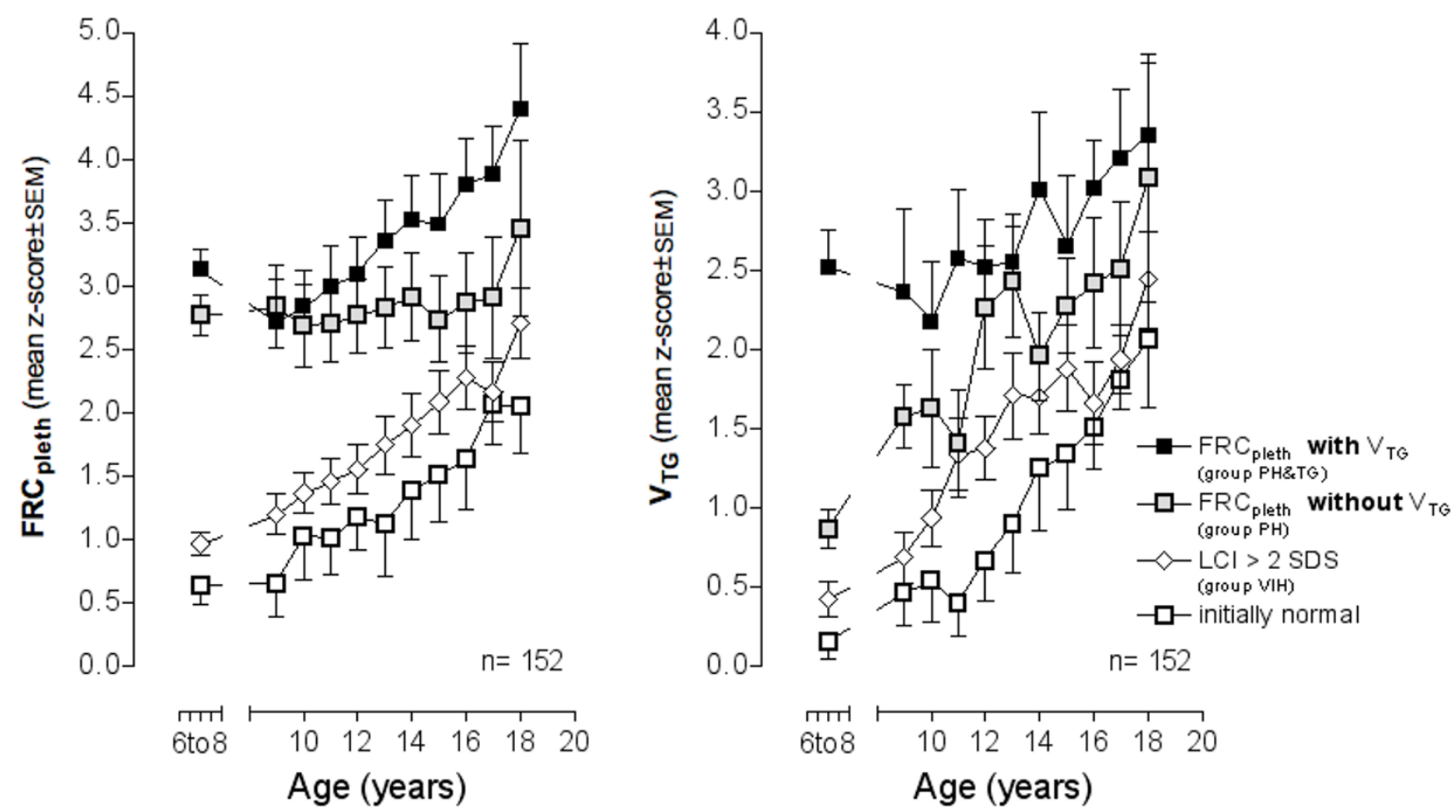

Figure 2

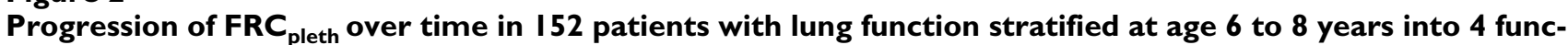
tional severity groups. Group PH\&TG (pulmonary hyperinflation and trapped gas): $\mathrm{FRC}_{\text {pleth }}$ and $\mathrm{V}_{\mathrm{TG}}>2 \mathrm{SDS}$; group PH (pulmonary hyperinflation without trapped gas): $\mathrm{FRC}_{\text {pleth }}>$ 2SDS; group VIH (ventilation inhomogeneities): LCI > 2SDS; group FN: functionally normal. 
to be significantly higher for LCI (5.077), and $\mathrm{FEV}_{1}$ (4.542, panel B). With the exception of LCI, significant differences in the values for the regression slope were found between CFTR genotype and lung function indices. The strongest associations were observed for $\mathrm{FEF}_{50}(F=$ $14.255, p<0.0001)$ and $\mathrm{FEV}_{1}(F=13.066, p<0.0001)$. $\mathrm{FEF}_{50}$ differentiated best between CFTR genotypes, if $\Delta \mathrm{F} 508(2)$ group was taken as the baseline value (Table 3, panel C). Children in whom the $\mathrm{R} 553 \mathrm{X} / \Delta \mathrm{F}$ mutation was present demonstrated the lowest values for all lung function parameters at time of initial measurement (age 6 to 8 yrs). Those with the $\Delta \mathrm{F} 508(2)$ mutation had higher initial values. Maximum values for parameters obtained at initial measurement were observed in the 3905ins group.

\section{Relationship between lung function and different combinations of infection}

The impact of different types of infection on progression of lung function is shown in Figure 3. Age and the 4 most frequent types of infection were taken as fixed effects and the patient-specific intercept as random effect. Children with chronic $P$. aeruginosa infection (PA) showed the most rapid rate of progression when examined for all lung function parameters. Within this group progressive changes in parameter values were most rapid for $\mathrm{FEF}_{50}$ (slope: 0.582) and $s R_{\text {eff }}$ (slope: 0.480). Group effects, i.e. initial already high intercept were detected for $\mathrm{FEV}_{1}$ (19.214), and LCI (7.345,). Significant relationships were identified between infection type and progression of lung function indexes, with strongest associations observed for $\mathrm{FEF}_{50}(F$ $=7.994, p<0.0001)$ and $\mathrm{FRC}_{\text {pleth }}(F=6.020, p<0.0001)$. Of all the groups in which infection was present, those with chronic $S$. aureus infection ( $S A$ ) showed the least aggressive rate of progression of functional index values. Interestingly, although not significant but as tendency observed for each lung function parameter, $P$. aeruginosa combined with other infection (PA_comb) presented with more progression than $P$. aeruginosa infection (PA) alone. LCI proved to be the index most sensitive for differentiating between infection types $(p<0.0001)$ when the group free of any colonization or infection was taken as baseline.

\section{Discussion}

This study demonstrates that progression of pulmonary hyperinflation and the presence of trapped gas are important mechanical features of disease evolution in patients with cystic fibrosis. Data analyzed from a cohort of $152 \mathrm{CF}$ patients, revealed the presence of pulmonary hyperinflation in more than one third $(37.5 \%)$ of cases as early as age 6 to 8 years. In half of these $(18.4 \%)$, pulmonary hyperinflation was associated with trapped gas. Both functional abnormalities deteriorated with age (Figure 2). Ventilation inhomogeneities have been previously shown to represent the earliest and most rapidly progressive func- tional abnormality in CF [16]. The current findings suggest that ventilation inhomogeneities are accompanied by steadily increasing hyperinflation, gas trapping, airway obstruction, and flow limitation. All patients identified as having increased $\mathrm{V}_{\mathrm{TG}}$ also demonstrated increased values for LCI. Rate of progression of functional abnormality was most rapid within a subgroup of patients within whom both pulmonary hyperinflation and trapped gas were present (Figure 2).

The relationships between pulmonary hyperinflation and gas trapping and deterioration of lung function in CF are presented here using longitudinal data. Previous investigations have demonstrated that pulmonary hyperinflation influences lung mechanics in terms of increased work of breathing, greater severity of breathlessness, impaired respiratory muscle function [53-58] and increased energy expenditure and oxygen consumption [55,56,59]. Recognition of functional deterioration is therefore critical to the ongoing management of patients with CF. Trapped gas occurs as a consequence of absent communicative pathways between small and large airways, thus reducing the alveolar surface area available for gas exchange $[37,42,60]$. Pulmonary hyperinflation and the development of trapped gas are closely associated with different types of chronic bronchial infection, especially P. aeruginosa (Figure 3). Of even greater interest, our results suggest that the CFTR genotype plays an important role in determining the longitudinal functional progression of lung disease in CF (Table 3).

Finally, this work in CF patients provides further confirmatory evidence for progressive tracking of lung function abnormalities already observed in other chronic respiratory illnesses such as bronchial asthma [27] and chronic lung disease of infancy [25]. Ranganathan et al. demonstrated tracking between parameters of airway function and growth in infants and young children [25]. Children with $\mathrm{CF}$ and better initial $\mathrm{FEV}_{1}$ have a slower rate of decline in lung function than those in whom initial $\mathrm{FEV}_{1}$ was already very low [61]. The authors concluded that young children with good pulmonary function and intercurrent pulmonary illness need not be treated as aggressively as children with documented lower $\mathrm{FEV}_{1}$. Our own data support this finding, since children with evidence of severe disease early in life experienced more aggressive functional deterioration over the course of the study period.

\section{Changes of lung volume during disease progression in CF} Elevation of FRC represents an almost universal accompaniment of significant intrathoracic airway obstruction. Elevated end-expiratory level in patients with severe lung disease is achieved by a strategy adopted to increase expiratory flow, especially during exercise. Patients thus meet 


\begin{tabular}{|c|c|c|c|c|c|c|c|c|c|c|c|c|c|}
\hline & & \multirow[t]{3}{*}{$A$} & \multirow{3}{*}{$\begin{array}{c}\begin{array}{c}\text { Progression with age } \\
\text { of lung function }\end{array} \\
\text { Slopes within groups }\end{array}$} & \multirow{3}{*}{ B } & \multicolumn{4}{|c|}{ Comparison of progression between genetic groups } & \multirow[t]{2}{*}{$\mathbf{C}$} & \multicolumn{2}{|c|}{$\begin{array}{l}\text { Comparison of progressions within } \\
\text { groups in relation to } \Delta \mathrm{F} 508(2) *\end{array}$} & \multirow[t]{3}{*}{$\mathbf{D}$} & \multirow[t]{3}{*}{$\begin{array}{c}\text { delta of Power } \\
\text { analysis } 0.8\end{array}$} \\
\hline & & & & & \multicolumn{2}{|c|}{$\begin{array}{c}\text { Intercept at age } 6 \text { to } 8 \text { yrs mean } \\
\text { comparison }\end{array}$} & \multicolumn{2}{|c|}{$\begin{array}{l}\text { Slope differences } \\
\text { (age range } 6 \text { to } 18 \mathrm{yrs} \text { ) }\end{array}$} & & & & & \\
\hline & & & & & F-value & sign. & F-value & sign. & & mean diff. & sign. & & \\
\hline \multirow[t]{3}{*}{ FRC $_{\text {pleth }}$} & $\Delta \mathrm{F} 508(2)$ & & 0.151 & & 1.117 & n.s. & 3.979 & 0.008 & & & & & \\
\hline & 3905ins T/AF & & 0.215 & & & & & & & 1.057 & 0.048 & & 0.09154 \\
\hline & $\mathrm{R} 553 \mathrm{X} / \Delta \mathrm{F}$ & & 0.165 & & & & & & & 0.120 & n.s. & & 0.09969 \\
\hline \multirow[t]{3}{*}{ LCl } & $\Delta \mathrm{F} 508(2)$ & & 0.247 & & 5.077 & 0.002 & 0.491 & n.s. & & & & & \\
\hline & $3905 \mathrm{ins} T / \Delta \mathrm{F}$ & & 0.291 & & & & & & & 1.865 & 0.006 & & 0.200854 \\
\hline & $\mathrm{R} 553 \mathrm{X} / \Delta \mathrm{F}$ & & 0.278 & & & & & & & 0.307 & n.s. & & 0.236018 \\
\hline \multirow[t]{3}{*}{$\mathbf{V}_{\text {TG }}$} & $\Delta \mathrm{F} 508(2)$ & & 0.198 & & 3.372 & 0.019 & 6.499 & 0.0001 & & & & & \\
\hline & $3905 \mathrm{ins} \mathrm{T} / \Delta \mathrm{F}$ & & 0.233 & & & & & & & 1.036 & 0.011 & & 0.113801 \\
\hline & $\mathrm{R} 553 \mathrm{X} / \Delta \mathrm{F}$ & & 0.256 & & & & & & & 0.065 & n.s. & & 0.128347 \\
\hline \multirow{3}{*}{$\mathbf{s} \mathbf{R}_{\text {eff }}$} & $\Delta \mathrm{F} 508(2)$ & & 0.405 & & 0.849 & n.s. & 10.043 & 0.0001 & & & & & \\
\hline & 3905ins T/ $/ \mathrm{F}$ & & 0.549 & & & & & & & 1.297 & n.s. & & 0.305402 \\
\hline & $\mathrm{R} 553 \mathrm{X} / \Delta \mathrm{F}$ & & 0.741 & & & & & & & 3.298 & 0.039 & & 0.328812 \\
\hline \multirow[t]{3}{*}{ FEV $_{1}$} & $\Delta \mathrm{F} 508(2)$ & & -0.185 & & 4.542 & 0.004 & 13.066 & 0.0001 & & & & & \\
\hline & $3905 \mathrm{ins} \mathrm{T} / \Delta \mathrm{F}$ & & -0.216 & & & & & & & 2.502 & 0.009 & & 0.16809 \\
\hline & $\mathrm{R} 553 \mathrm{X} / \Delta \mathrm{F}$ & & -0.466 & & & & & & & 0.431 & n.s. & & 0.18238 \\
\hline \multirow[t]{4}{*}{ FEF $_{50}$} & $\Delta \mathrm{F} 508(2)$ & & -0.439 & & 1.774 & n.s. & 14.255 & 0.0001 & & & & & \\
\hline & 3905ins T/AF & & -0.738 & & & & & & & 1.011 & n.s. & & 0.30235 \\
\hline & $\mathrm{R} 553 \mathrm{X} / \Delta \mathrm{F}$ & & -1.029 & & & & & & & 2.952 & 0.002 & & 0.32759 \\
\hline & Misc & & -0.354 & & & & & & & & & & \\
\hline
\end{tabular}


$\mathrm{FRC}_{\text {pleth }}$

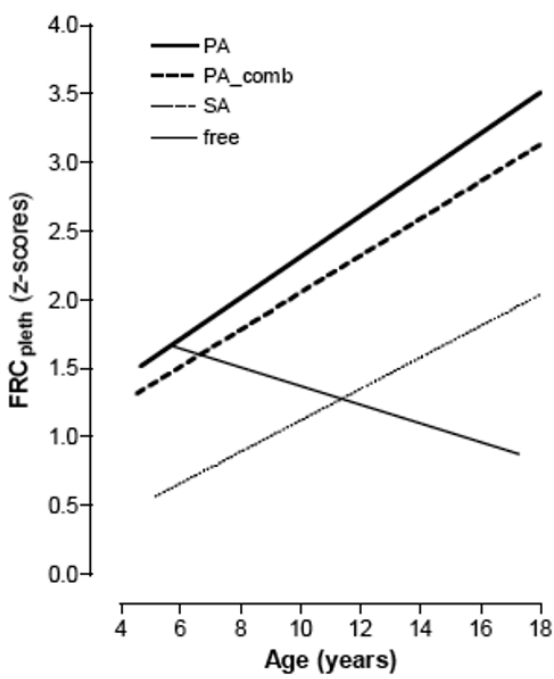

$s R_{\text {eff }}$

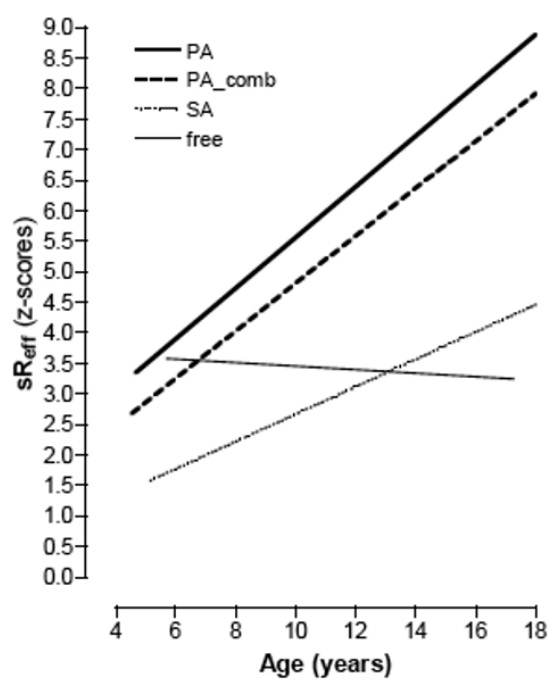

$\mathrm{LCl}$

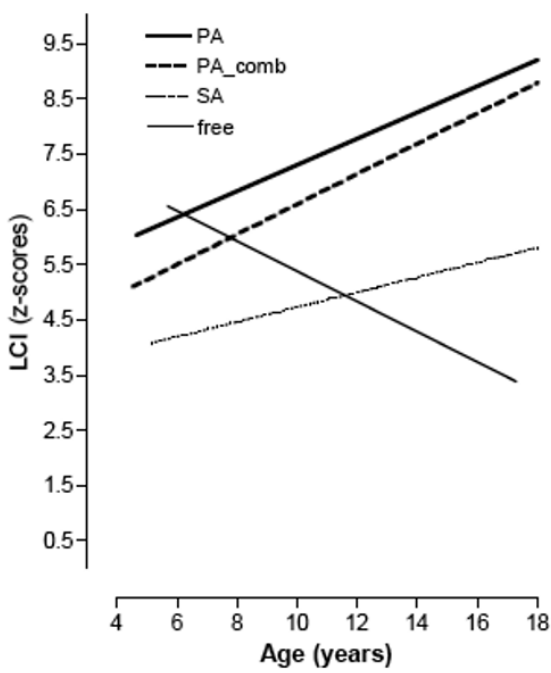

$\mathrm{FEV}_{1}$

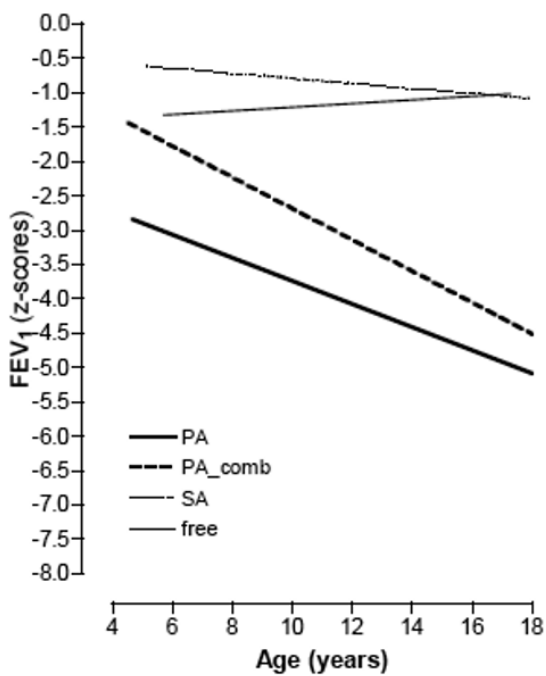

$\mathbf{V}_{\mathrm{TG}}$

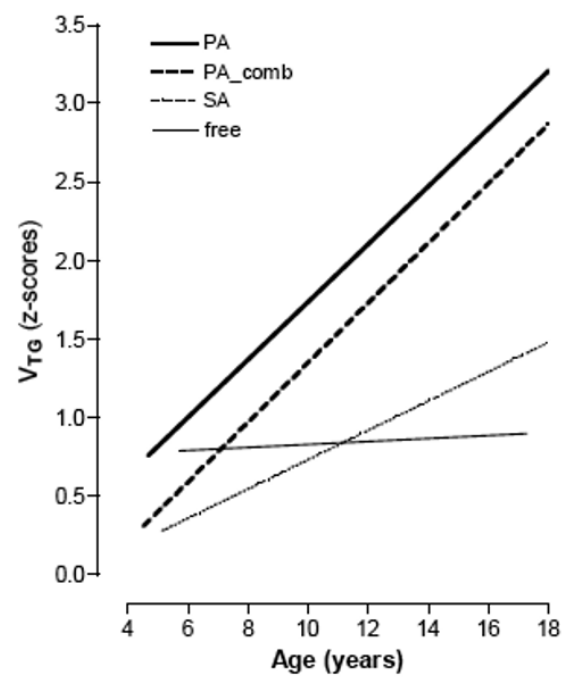

$\mathrm{FEF}_{50}$

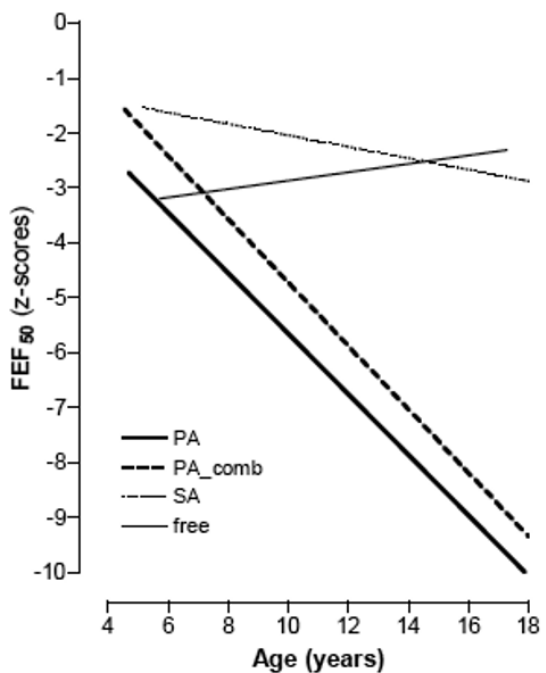

Figure 3

Progression with age within 5 different types of colonization or infection respectively, depicted for each lung function parameter. Slopes were calculated from the fixed values predicted according to group using linear mixed-effect model analysis. (PA: chronically infected by P. aeruginosa; PA_comb: chronically infected by P. aeruginosa and other bacteria; SA: chronically infected only by S. aureus; intermit.: intermittently colonized by several bacteria; free: free from any bacterial colonisations).

their ventilatory requirements at rest by increasing breathing frequency rather than tidal volume in order to minimize the increase of resistive work associated with thoracic wall excursion. However, pulmonary hyperinflation affects respiratory muscle function [62]. Elevation of end-expiratory level above relaxation volume places an extra load on the inspiratory musculature at end-expiration, whereby an additional "threshold" load related to the elastic recoil of the respiratory system must be over- come prior to commencement of inspiratory flow. Hyperinflation, together with loss of static recoil occurring in relation to airflow limitation results in altered respiratory muscle function $[55,56]$. There continues to be only limited understanding of how respiratory muscle function is altered in patients with hyperinflation. Animal experiments indicate that hyperinflation is detrimental to the functional effectiveness of the diaphragm, but may provide mechanical benefit to the parasternal intercostals 
[63]. Patients with severe hyperinflation demonstrate more pronounced diaphragmatic shortening than intercostal and accessory muscle shortening [64]. These patients also exhibit clear signs of reduced diaphragmatic functional capacity which correlates with the degree of airflow obstruction $[64,65]$. Studies of interactions between pulmonary hyperinflation and inspiratory muscle function have highlighted the reduced muscular efficiency and predisposition to fatigue occurring in CF [57].

Preferential impairment of the peripheral skeletal musculature is frequently seen in patients with CF. Typically, respiratory muscle strength is preserved while the quadriceps is weakened [56]. This observation is consistent with the diaphragm benefiting from a continuous training stimulus secondary to increased inspiratory impedance. Therefore, hyperinflation does not impair force generation of the diaphragm to the same extent in cystic fibrosis as may occur in other chronic respiratory diseases. Normal inspiratory muscle strength is commonly observed in CF and diaphragmatic adaptation in this condition may extend beyond that usually observed in adult COPD, where maximal diaphragmatic strength is lower than in normal individuals. The relative contribution of inspiratory musculature to overall respiratory muscle weakness in CF patients has also been assessed [66]. Major determinants of inspiratory muscle weakness include muscle mass, hyperinflation, gas trapping and to a lesser extent nutritional status [56]. Thus, gradual deterioration in pulmonary function, together with an associated increase in work of breathing and inspiratory muscle weakness all play important roles in the development of ventilatory failure $[53,54,57,58]$.

\section{The role of the development of trapped gas}

Identification of early pulmonary hyperinflation associated with trapped gas as the most severe functional group during childhood and adolescence may represent an early warning signal. Early gas trapping in this setting appears to progress to persistent and ongoing disruption of lung mechanics, leading to impairment of gas exchange $[60,67-$ $71]$, increased energy expenditure [59,72], and disruption of normal chest wall motion and exercise performance [73]. Together with chronic infection, poor energy intake and a catabolic state $[55,56,59]$, further deterioration of respiratory muscle function occurs $[55,56]$. A reduction in trapped gas volume in association with improved maximal working capacity is observed in CF patients following long-term chest physiotherapy $[74,75]$. In normal subjects, expiration to residual volume results in a degree of small airway closure, some atelectasis of dependent lung regions and gas trapping [76]. The extent to which this occurs is related to age [77], as highlighted recently by Milic-Emili [78]. Closure of small airways results in discontinuity of expiratory airflow. Healthy subjects main- tain FRC above a critical volume at which airway closure occurs (closing volume) and therefore demonstrate no gas trapping [79]. In young children, closing volume and FRC approximate each other closely [79], thus further potentiating gas trapping. In the presence of disease, and particularly in $\mathrm{CF}$, impaired airway clearance mechanisms and inflammatory changes associated with chronic infection disrupt small airway patency, leading to discontinuity and limitation of expiratory airflow. Loss of static recoil associated with pulmonary hyperinflation may further aggravate this process [80] and increase the potential for gas trapping[79]. We have recently shown that an index of ventilation inhomogeneity, the LCI, progresses with age in patients with CF, particularly after the onset of chronic $P$. aeruginosa infection [16] and allergic bronchopulmonary aspergillosis (ABPA) [41]. Whilst an increase in gas trapping results in a concordant rise in ventilation inhomogeneities, the degree to which airway closure occurs will also depend upon the age-dependant relationship between FRC and closing volume and on airway resistance $[77,79,81-83]$. Since the separation between FRC and closing volume is likely to be reduced at younger ages, the appearance of severe ventilation inhomogeneities and pulmonary hyperinflation in this age group may predispose towards early gas trapping and earlier onset of age related progression of lung function deterioration (tracking). Early identification of gas trapping may therefore be critical to instituting therapeutic measures aimed at retarding or reversing this situation.

\section{Relationship between CFTR genotypes and progression of hyperinflation and gas trapping}

A relationship between CFTR genotype and severity of pulmonary disease in CF has proven difficult to establish. Nevertheless, the variability of pulmonary function at time of diagnosis in infants [21] and children [84-86] has been found to be partially related to the genotype. In comparison to the inframe homozygotes $\Delta \mathrm{F} 508(2)$ and nonsense $\mathrm{R} 553 \mathrm{X} / \Delta \mathrm{F}$ compound heterozygotes, patients carrying one frameshift mutation 3905insT have a poorer prognosis with respect to the onset of pulmonary disease, progression of lung function, and mortality [87]. Schaedel et al. used $\mathrm{FEV}_{1} \%$ normal predicted to demonstrate a slower rate of decline in patients with missense mutations compared with $\Delta$ F508(2) homozygotes [86], and Cory et al. used LMM analysis to show a slower rate of pulmonary function decline in some patients with non- $\Delta$ F508 mutations [51]. We undertook a similar statistical approach to evaluate potential associations between repeated lung function measurements and the most frequent CFTR genotypes in Switzerland, $\Delta \mathrm{F} 508(2), \quad 3905 \mathrm{insT} / \Delta \mathrm{F}$ and $\mathrm{R} 553 \mathrm{X} / \Delta \mathrm{F}$. Significant differences in lung function indices were identified between the 3905ins $\mathrm{T} / \Delta \mathrm{F}$ compound heterozygote and $\Delta \mathrm{F} 508(2)$ homozygote mutation groups for $\mathrm{FRC}_{\text {pleth' }}$ LCI and $\mathrm{V}_{\mathrm{TG}^{\prime}}$ as well as between $\mathrm{R} 553 \mathrm{X} / \Delta \mathrm{F}$ 
compound heterozygotes and $\Delta \mathrm{F} 508(2)$ homozygotes for sReff, and $\mathrm{FEF}_{50}$ (Table 3). Confirming previous findings $[15,21,51,88,89]$, our data demonstrate that the 3905ins $T$ mutation is associated with severe lung disease, manifesting early in life [21], whereas the $\mathrm{R} 553 \mathrm{X} / \Delta \mathrm{F}$ mutation seems to provide milder pulmonary involvement during the first 5 to 6 yrs of life, thereafter however, to be exposed to a much more pronounced progression compared with both the $\Delta \mathrm{F} 508$ and the $3905 \mathrm{insT} / \Delta \mathrm{F}$. In addition, regressions of fixed predicted values obtained by the LMM analysis indicate significantly higher rates of progression of small airway disease in patients within the $3905 \mathrm{insT} / \Delta \mathrm{F}$ group compared to $\Delta \mathrm{F} 508(2)$ homozygotes. The effect is even more pronounced for the R553X/ $\Delta \mathrm{F}$ group. Thus, we conclude that CFTR genotypes clearly act as an important determinant of disease progression and hence outcome, when lung function parameters are interpreted in terms of variance-based data ( $z$-scores), and in relation to genderand age-specific regression equations [38-40].

\section{The role of environmental factors}

In the present study patients chronically colonized with $P$. aeruginosa showed a significantly worse disease course (Figure 3) compared to other types of infection. This was especially the case in relation to ventilation inhomogeneities. This finding is consistent with observations of Wilmott et al. showing a strong association between $P$. aeruginosa status and mortality [90], and the associations between $\mathrm{FEV}_{1}$ and $P$. aeruginosa infection found by Kerem et al [91]. More noteworthy, is the finding that in addition to age of onset of chronic $P$. aeruginosa infection, colonization status at the time of lung function evaluation is important.

\section{Methodological limitations}

The current study represents a very large patient cohort, many of whom were followed up over a long time period. An important limitation of these types of data resides in the ability to obtain repeated measurements of lung function annually, over a substantial range of time. However, we obtained serial annual measurements over a 10 -year period in at least $50 \%$ of the children. Linear mixed-effects model analysis provides an ideal statistical method for the interpretation of repeated measurement data such as these, particularly when repeated testing results in small proportions of incomplete data. A second potential influence on the results of this type of analysis involves the use of subgroups, since the relatively small number of patients within each group may result in relatively high levels of variability. The adequacy of stratification within subgroups is critical to the interpretation of differences observed in outcome measures between each subgroup. Whilst stratification of bronchial infection subgroups was adequate, stratification of specific CFTR genotypes required a frequency based approach to search for signifi- cant associations. This finding may be intriguing for some research groups where genotype-phenotype associations with pulmonary involvement have not been able to be identified in CF. Whilst well-established associations between pancreatic insufficiency and genotype are recognised based on a clear "on-off" selection, studies investigating lung function indexes and genotype associations may need to consider several functional parameters in order to clearly identify those likely to be affected by mutational changes. Our results suggest that parameters representing pulmonary hyperinflation, ventilation inhomogeneities, gas trapping and airway narrowing are required to be considered in addition to those quantifying the degree of bronchial obstruction. Moreover, lung function data must be presented in a form independent of gender and growth status (z-transformation). The current study presents longitudinal data and expresses changes in SDS in terms of cross-sectional reference equations [16]. The volume of trapped gas was calculated as the difference between FRC measured plethysmographically $\left(\mathrm{FRC}_{\text {pleth }}\right)$ and by the FRC obtained by gas washout $\left(\mathrm{FRC}_{\mathrm{MBNW}}\right)$. It must be borne in mind that the difference between these two values provides an index that correlates with trapped gas, but is not equal to trapped gas. In the presence of significant airway obstruction, FRC is overestimated by plethysmography. However, we used a non-panting method that reduces this artifact by allowing greater time for equilibration between alveolar and mouth pressure. Finally, genotype-phenotype association studies investigating pulmonary involvement in $\mathrm{CF}$ are complex and require determination of factors such as available lung function parameters and duration of life span during which data are acquired. A specific question is how the genetic background should be categorized. Possible categorizations might include $\Delta \mathrm{F} 508$ versus non- $\Delta \mathrm{F} 508$, or in terms of molecular mechanisms and consequences observed at the gene or protein level. It has to be kept in mind, that our cohort study represents primarily the CFTR genotype distribution for Switzerland, where a substantial proportion of patients carry the severe $\mathrm{CF}$ mutation (3905ins $/ \Delta \mathrm{F}$ ), which is associated with the highest mortality rate $[21,37,44,88]$.

\section{Summary}

This study demonstrates that pulmonary hyperinflation and development of trapped gas represent major functional features of disease progression in children with CF. Children with severe pulmonary hyperinflation and gas trapping at age 6-8 y have the most significant rate of disease progression over time. As has been reported previously in childhood asthma, tracking of lung function abnormalities in CF commences early in life, and is considerably influenced by the CFTR genotype. Furthermore, the present study shows that $\mathrm{FRC}_{\text {pleth}}$ and hence the degree of pulmonary hyperinflation best differentiate 
between different types of bronchial infection. Chronic $P$. aeruginosa infection appears to be the most important infective contributor to disease progression. The observed associations between CFTR genotypes and lung function characteristics, as well as the associations between different types of bronchial infection with pulmonary hyperinflation stress the need to include a range of tests when assessing these patients, rather than relying simply on spirometry. Early assessment of airway obstruction, pulmonary hyperinflation and gas trapping in addition to ventilation inhomogeneities and in conjunction with CFTR genotyping provides a means for monitoring functional progression in $\mathrm{CF}$ disease.

\section{Abbreviations}

BTPS: body temperature and pressure saturated

\section{CF: Cystic Fibrosis}

CFTR: Cystic Fibrosis Transmembrane conductance Regulator

DNA: Deoxyribonucleid Acid

FEV1: Forced Expiratory Volume in One second

$\mathrm{FEF}_{50}$ : Forced expiratory flow at 50 percent FVC

$\mathrm{FRC}_{\text {pleth }}$ : Functional residual capacity (plethysmographically determined)

FRC $_{\text {MBNW: }}$ Functional residual capacity (determined by MBNW)

FVC: Forced Vital Capacity

LCI: Lung clearance index

LMM: Linear mixed model

MBNW: Multibreath nitrogen washout

PA: Pseudomonas aeruginosa

SA: Staphylococcus aureus

SDS: Standard deviation score

SEM: Stardard error of the mean

$\mathrm{sR}_{\text {eff: }}$ : specific effective airway resistance

SSCP/HD: single strand confirmation polymorphism/heteroduplex
TLC: Total Lung Capacity

$\mathrm{V}_{\mathrm{TG}}$ : volume of trapped gas

\section{Competing interests}

The author(s) declare that they have no competing interests.

\section{Authors' contributions}

RK designed, coordinated and conceived the study.

DB took part in the interpretation of data and manuscript revision.

RA participated in the data collection, interpretation of data and manuscript revision

UF took part in the interpretation of data and revised the draft.

SG performed the CF mutation screening, took part in the interpretation of data (especially genetics) and revising.

All authors read and approved the final manuscript.

\section{Funding}

The study was supported by grants of the Swiss National Research Foundation (SNF 3200-040681.94_SG, 32040562.95_RK, 3200-055697.98_SG, 32066767.02_SG) and the Foundation Telethon Action Switzerland. Dr. Baldwin was a fellow in the ERS Long Term Research Program.

\section{Acknowledgements}

The authors are indebted to Prof. Martin H. Schöni, M.D., Dr. Anna Rüdeberg, M.D., Dr. Carmen Casaulta-Aebischer, M.D., Dr. Andrea Blum, M.D., and the entire nursing staff of the Bernese Cystic Fibrosis Clinic for their contribution in collecting the clinical data and in obtaining the samples for genotype analysis. The authors also thank Ms. Gisela Wirz for performing the lung function tests and database management.

\section{References}

I. Rowe SM, Miller S, Sorscher E]: Cystic fibrosis. N Engl J Med 2005, 352(19): 1992-200I.

2. Boucher RC: New concepts of the pathogenesis of cystic fibrosis lung disease. Eur Respir / 2004, 23(I): 1 46- I58.

3. Mall M, Grubb BR, Harkema JR, O'Neal WK, Boucher RC: Increased airway epithelial $\mathrm{Na}+$ absorption produces cystic fibrosis-like lung disease in mice. Nat Med 2004, I0(5):487-493.

4. Matsui H, Grubb BR, Tarran R, Randell SH, Gatzy JT, Davis CW, Boucher RC: Evidence for periciliary liquid layer depletion, not abnormal ion composition, in the pathogenesis of cystic fibrosis airways disease. Cell 1998, 95(7): 1005-1015.

5. Worlitzsch D, Tarran R, Ulrich M, Schwab U, Cekici A, Meyer KC, Birrer P, Bellon G, Berger J, Weiss T, et al.: Effects of reduced mucus oxygen concentration in airway Pseudomonas infections of cystic fibrosis patients. J Clin Invest 2002, 109(3):317-325.

6. Regnis JA, Robinson M, Bailey DL, Cook P, Hooper P, Chan HK, Gonda I, Bautovich G, Bye PT: Mucociliary clearance in patients 
with cystic fibrosis and in normal subjects. Am J Respir Crit Care Med 1994, I50(I):66-7I.

7. Wine J]: The genesis of cystic fibrosis lung disease. J Clin Invest 1999, 103(3):309-312.

8. Chmiel JF, Davis PB: State of the Art: Why do the lungs of patients with cystic fibrosis become infected and why can't they clear the infection? Respir Res 2003, 4(I):8.

9. Tarran R, Button B, Boucher RC: Regulation of normal and cystic fibrosis airway surface liquid volume by phasic shear stress. Annu Rev Physiol 2006, 68:543-56I.

10. Tarran R, Button B, Picher M, Paradiso AM, Ribeiro CM, Lazarowski ER, Zhang L, Collins PL, Pickles RJ, Fredberg J], et al.: Normal and cystic fibrosis airway surface liquid homeostasis. The effects of phasic shear stress and viral infections. J Biol Chem 2005, 280(42):3575 I-35759.

11. Wood R: Prognosis. In Cystic fibrosis Edited by: Taussig LM. New York: Thieme-Stratton; 1984:434-460.

12. Konstan MW, Hilliard KA, Norvell TM, Berger M: Bronchoalveolar lavage findings in cystic fibrosis patients with stable, clinically mild lung disease suggest ongoing infection and inflammation. Am J Respir Crit Care Med 1994, I 50(2):448-454.

13. Cystic Fibrosis Foundation National Patient Registry. In Annual Data Report 2003 Bethesda, Md: Cystic Fibrosis Foundation; 2003.

14. Kerem E, Corey M, Kerem BS, Rommens J, Markiewicz D, Levison H, Tsui LC, Durie P: The relation between genotype and phenotype in cystic fibrosis - analysis of the most common mutation (delta F508). N Engl J Med 1990, 323(22): I5 I7-1522.

15. Kerem E, Reisman J, Corey M, Canny G], Levison H: Prediction of mortality in patients with cystic fibrosis. N Engl J Med 1992, 326(I8): I| |87-II9|.

16. Kraemer R, Blum A, Schibler A, Ammann RA, Gallati S: Ventilation inhomogeneities in relation to standard lung function in patients with cystic fibrosis. Am J Respir Crit Care Med 2005, I 7 I(4):37|-378.

17. Aurora P, Bush A, Gustafsson P, Oliver C, Wallis C, Price J, Stroobant J, Carr S, Stocks J: Multiple-breath washout as a marker of lung disease in preschool children with cystic fibrosis. Am J Respir Crit Care Med 2005, I7I(3):249-256.

18. Beardsmore CS, Bar-Yishay E, Maayan C, Yahav Y, Katznelson D, Godfrey S: Lung function in infants with cystic fibrosis. Thorax I988, 43(7):545-55 |.

19. Kraemer R: Early detection of lung function abnormalities in infants with cystic fibrosis. $J R$ Soc Med 1989, 82(Suppl 16):21-25.

20. Beardsmore CS: Lung function from infancy to school age in cystic fibrosis. Arch Dis Child 1995, 73(6):519-523.

21. Kraemer R, Birrer P, Liechti-Gallati S: Genotype-phenotype association in infants with cystic fibrosis at the time of diagnosis. Pediatr Res 1998, 44(6):920-926.

22. Gustafsson PM, Kallman S, Ljungberg $H$, Lindblad A: Method for assessment of volume of trapped gas in infants during multiple-breath inert gas washout. Pediatr Pulmonol 2003, 35(I):42-49

23. Corey M, Farewell V: Determinants of mortality from cystic fibrosis in Canada, 1970-1989. Am 」 Epidemiol 1996, 143(10): $1007-1017$

24. Assael BM, Castellani C, Ocampo MB, lansa P, Callegaro A, Valsecchi MG: Epidemiology and survival analysis of cystic fibrosis in an area of intense neonatal screening over $\mathbf{3 0}$ years. Am J Epidemiol 2002, I 56(5):397-40I.

25. Ranganathan SC, Stocks J, Dezateux C, Bush A, Wade A, Carr S, Castle R, Dinwiddie R, Hoo AF, Lum S, et al.: The evolution of airway function in early childhood following clinical diagnosis of cystic fibrosis. Am J Respir Crit Care Med 2004, 169(8):928-933.

26. Nielsen KG, Pressler T, Klug B, Koch C, Bisgaard H: Serial lung function and responsiveness in cystic fibrosis during early childhood. Am J Respir Crit Care Med 2004, 169(II):I209-1216.

27. Sears MR, Greene JM, Willan AR, Wiecek EM, Taylor DR, Flannery EM, Cowan JO, Herbison GP, Silva PA, Poulton R: A longitudinal, population-based, cohort study of childhood asthma followed to adulthood. N Engl J Med 2003, 349(I 5): | |4|4-|422.

28. Horak E, Lanigan A, Roberts M, Welsh L, Wilson J, Carlin JB, Olinsky A, Robertson CF: Longitudinal study of childhood wheezy bronchitis and asthma: outcome at age 42. Bmj 2003, 326(7386):422-423.
29. Filippone M, Sartor M, Zacchello F, Baraldi E: Flow limitation in infants with bronchopulmonary dysplasia and respiratory function at school age. Lancet 2003, 36I(9359):753-754.

30. Aurora P, Gustafsson P, Bush A, Lindblad A, Oliver C, Wallis CE, Stocks J: Multiple breath inert gas washout as a measure of ventilation distribution in children with cystic fibrosis. Thorax 2004, 59( I 2): 1068-1073.

31. Warwick WJ, Pogue RE, Gerber HU, Nesbitt CJ: Survival patterns in cyctic fibrosis. J Chronic Dis 1975, 28(I I-1 2):609-622.

32. Stern RC: The diagnosis of cystic fibrosis. N Engl J Med 1997, 336(7):487-491.

33. Rosenstein BJ, Cutting GR: The diagnosis of cystic fibrosis: a consensus statement. Cystic Fibrosis Foundation Consensus Panel. J Pediatr 1998, I32(4):589-595.

34. Liechti-Gallati S, Schneider V, Neeser D, Kraemer R: Two buffer PAGE system-based SSCP/HD analysis: a general protocol for rapid and sensitive mutation screening in cystic fibrosis and any other human genetic disease. Eur J Hum Genet 1999. 7(5):590-598.

35. Bennett LC, Kraemer R, Liechti-Gallati S: Buccal cell DNA analysis in premature and term neonates: screening for mutations of the complete coding region for the cystic fibrosis transmembrane conductance regulator. Eur J Pediatr 2000, I59(I2):99-102.

36. Kraemer R, Meister B: Fast real-time moment-ratio analysis of multibreath nitrogen washout in children. J Appl Physiol 1985, 59(4): I I37-II 44

37. Kraemer $\mathrm{R}$, Schoni $\mathrm{MH}$ : Ventilatory inequalities, pulmonary function and blood oxygenation in advanced states of cystic fibrosis. Respiration 1990, 57(5):318-324.

38. Kraemer R, Zehnder M, Meister B: Intrapulmonary gas distribution in healthy children. Respir Physiol 1986, 65(2): I27-137.

39. Zapletal A, Samanek M, Paul T: Lung function in children and adolescents. Basel (Switzerland): Karger; 1987.

40. Manzke H, Stadlober E, Schellauf HP: Combined body plethysmographic, spirometric and flow volume reference values for male and female children aged 6 to 16 years obtained from "hospital normals". Eur J Pediatr 200I, 160(5):300-306.

4I. Kraemer R, Delosea N, Ballinari P, Gallati S, Crameri R: Effect of allergic bronchopulmonary aspergillosis on lung function in children with cystic fibrosis. Am J Respir Crit Care Med 2006, I74(II): $1211-1220$.

42. Hamutcu R, Rowland JM, Horn MV, Kaminsky C, MacLaughlin EF, Starnes VA, Woo MS: Clinical findings and lung pathology in children with cystic fibrosis. Am J Respir Crit Care Med 2002, 165(8): I I72-1 I75.

43. Bennett LC, Kraemer R, Liechti-Gallati S: Buccal cell DNA analysis in premature and term neonates: screening for mutations of the complete coding region for the cystic fibrosis transmembrane conductance regulator. Eur J Pediatr 2000, 159:99-102.

44. Gallati S: Genetics of cystic fibrosis. In Cystic fibrosis and bronchiectasis Volume 24. Edited by: Lynch JP. New York, NY: Thieme Medical Publishers, Inc; 2003:629-637.

45. Steiner B, Truninger K, Sanz J, Schaller A, Gallati S: The role of common single-nucleotide polymorphisms on exon 9 and exon I 2 skipping in nonmutated CFTR alleles. Hum Mutat 2004 24(2): $120-129$.

46. Microbiology and infectious disease in cystic fibrosis. In Consensus conference: concept of care edn Volume 5. Bethesda, MD: Cystic Fibrosis Foundation; 1994. sect I

47. Schaad UB, Wedgwood-Krucko J, Guenin K, Buehlmann U, Kraemer $\mathrm{R}$ : Antipseudomonal therapy in cystic fibrosis: aztreonam and amikacin versus ceftazidime and amikacin administered intravenously followed by oral ciprofloxacin. Eur J Clin Microbiol Infect Dis 1989, 8(10):858-865.

48. Dibley MJ, Goldsby JB, Staehling NW, Trowbridge FL: Development of normalized curves for the international growth reference: historical and technical considerations. Am J Clin Nutr 1987, 46(5):736-748.

49. Laird NM, Ware JH: Random-effects models for longitudinal data. Biometrics 1982, 38(4):963-974.

50. Laird NM, Donnelly C, Ware JH: Longitudinal studies with continuous responses. Stat Methods Med Res 1992, I(3):225-247.

5I. Corey M, Edwards L, Levison H, Knowles M: Longitudinal analysis of pulmonary function decline in patients with cystic fibrosis. J Pediatr 1997, 13 I(6):809-814. 
52. Edwards LJ: Modern statistical techniques for the analysis of longitudinal data in biomedical research. Pediatr Pulmonol 2000, 30(4):330-344.

53. Szeinberg A, England S, Mindorff C, Fraser IM, Levison H: Maximal inspiratory and expiratory pressures are reduced in hyperinflated, malnourished, young adult male patients with cystic fibrosis. Am Rev Respir Dis 1985, I32(4):766-769.

54. Mier A, Redington A, Brophy C, Hodson M, Green M: Respiratory muscle function in cystic fibrosis. Thorax 1990, 45( I 0):750-752.

55. Zapletal A, Desmond KJ, Demizio D, Coates AL: Lung recoil and the determination of airflow limitation in cystic fibrosis and asthma. Pediatr Pulmonol 1993, I 5(I): I3-18.

56. Lands LC, Heigenhauser GJ, Jones NL: Respiratory and peripheral muscle function in cystic fibrosis. Am Rev Respir Dis 1993 , | 47(4):865-869.

57. Hayot M, Guillaumont S, Ramonatxo M, Voisin M, Prefaut C: Determinants of the tension-time index of inspiratory muscles in children with cystic fibrosis. Pediatr Pulmonol 1997, 23(5):336-343.

58. Pinet C, Cassart M, Scillia P, Lamotte M, Knoop C, Casimir G, Melot $C$, Estenne M: Function and bulk of respiratory and limb muscles in patients with cystic fibrosis. Am J Respir Crit Care Med 2003, I 68(8):989-994.

59. Askanazi J, Weissman C, Rosenbaum SH, Hyman Al, Milic-Emili J, Kinney JM: Nutrition and the respiratory system. Crit Care Med 1982, I0(3): 163-172

60. Coates AL, Canny G, Zinman R, Grisdale R, Desmond K, Roumeliotis $D$, Levison $H$ : The effects of chronic airflow limitation, increased dead space, and the pattern of ventilation on gas exchange during maximal exercise in advanced cystic fibrosis. Am Rev Respir Dis I988, I38(6): |524-I53I.

61. Zemel BS, Jawad AF, FitzSimmons S, Stallings VA: Longitudinal relationship among growth, nutritional status, and pulmonary function in children with cystic fibrosis: analysis of the Cystic Fibrosis Foundation National CF Patient Registry. J Pediatr 2000, I 37(3):374-380.

62. Decramer $M$ : Hyperinflation and respiratory muscle interaction. Eur Respir J 1997, I0(4):934-941.

63. Decramer M, Jiang TX, Demedts M: Effects of acute hyperinflation on chest wall mechanics in dogs. J Appl Physiol 1987, 63(4): $1493-1498$.

64. Sharp JT, Goldberg NB, Druz WS, Fishman HC, Danon J: Thoracoabdominal motion in chronic obstructive pulmonary disease. Am Rev Respir Dis 1977, I I 5(I):47-56.

65. Gilmartin J], Gibson G]: Abnormalities of chest wall motion in patients with chronic airflow obstruction. Thorax 1984, 39(4):264-27I.

66. Hayot M, Guillaumont S, Ramonatxo M, Voisin M, Prefaut C: Deter minants of the tension-time index of inspiratory muscles in children with cystic fibrosis [see comments]. Pediatr Pulmonol 1997, 23:336-343.

67. Christensson P, Arborelius M Jr, Kautto R: Volume of trapped gas in lungs of healthy humans. J Appl Physiol I 98I, 5 I (I): I72-I75.

68. Gaultier C, Beaufils F, Boule M, Bompard Y, Devictor D: Lung functional follow-up in children after severe viral infection. Eur J Respir Dis 1984, 65(6):460-467.

69. Gibson GJ: Pulmonary hyperinflation a clinical overview. Eur Respir J 1996, 9(12):2640-2649.

70. Leith DE, Brown R: Human lung volumes and the mechanisms that set them. Eur Respir J 1999, I3(2):468-472.

7I. Palecek F: Hyperinflation: control of functional residual lung capacity. Physiol Res 200I, 50(3):22I-230.

72. Donahoe M, Rogers RM, Wilson DO, Pennock BE: Oxygen consumption of the respiratory muscles in normal and in $\mathrm{mal}$ nourished patients with chronic obstructive pulmonary disease. Am Rev Respir Dis 1989, I40(2):385-391.

73. Bellemare JF, Cordeau MP, Leblanc $P$, Bellemare F: Thoracic dimensions at maximum lung inflation in normal subjects and in patients with obstructive and restrictive lung diseases. Chest 200I, I I 9(2):376-386.

74. Andreasson B, Jonson B, Kornfalt R, Nordmark E, Sandstrom S: Long-term effects of physical exercise on working capacity and pulmonary function in cystic fibrosis. Acta Paediatr Scand 1987, 76(I):70-75.

75. Groth S, Stafanger G, Dirksen H, Andersen JB, Falk M, Kelstrup M Positive expiratory pressure (PEP-mask) physiotherapy improves ventilation and reduces volume of trapped gas in cystic fibrosis. Bull Eur Physiopathol Respir 1985, 2 I (4):339-343.

76. Milic-Emili J, Henderson JA, Dolovich MB, Trop D, Kaneko K: Regional distribution of inspired gas in the lung. J Appl Physiol 1966, 2 I (3):749-759.

77. Mansell A, Bryan C, Levison H: Airway closure in children. J Appl Physiol 1972, 33(6):7II-7|4.

78. Milic-Emili J: Regional distribution of gas in the lung. Can Respir J 2000, 7(I):7I-76.

79. Anthonisen NR, Danson J, Robertson PC, Ross WR: Airway closure as a function of age. Respir Physiol 1969, 8(I):58-65.

80. Desmond KJ, Coates AL, Martin JG, Beaudry PH: Trapped gas and airflow limitation in children with cystic fibrosis and asthma. Pediatr Pulmonol 1986, 2(3): I28-I34.

8I. Hogg JC, Williams J, Richardson JB, Macklem PT, Thurlbeck WM: Age as a factor in the distribution of lower-airway conductance and in the pathologic anatomy of obstructive lung disease. N Engl J Med I970, 282(23): | 283-I 287.

82. Mansell $A L$, Bryan $A C$, Levison $H$ : Relationship of lung recoil to lung volume and maximum expiratory flow in normal children. J Appl Physiol I 977, 42(6):8I 7-823.

83. Cooper DM, Mellins RB, Mansell AL: Changes in distribution of ventilation with lung growth. J Appl Physiol I98I, 5 I (3):699-705.

84. Kerem E, Kerem $B$ : The relationship between genotype and phenotype in cystic fibrosis. Curr Opin Pulm Med 1995, I(6):450-456

85. Kerem E, Kerem B: Genotype-phenotype correlations in cystic fibrosis. Pediatr Pulmonol 1996, 22(6):387-395.

86. Schaedel C, de Monestrol I, Hjelte L, Johannesson M, Kornfalt R, Lindblad A, Strandvik B, Wahlgren L, Holmberg L: Predictors of deterioration of lung function in cystic fibrosis. Pediatr Pulmonol 2002, 33(6):483-49l.

87. Schibler A, Bolt I, Gallati S, Schoni MH, Kraemer R: High morbidity and mortality in cystic fibrosis patients compound heterozygous for 3905insT and deltaF508. Eur Respir J 200I, I7(6): I| $181-1 \mid 86$

88. Liechti-Gallati S, Bonsall I, Malik N, Schneider V, Kraemer LG, Ruedeberg A, Moser H, Kraemer R: Genotype/phenotype association in cystic fibrosis: analyses of the delta F508, R553X, and 3905ins T mutations. Pediatr Res 1992, 32(2): I75-I78.

89. Drumm ML, Konstan MW, Schluchter MD, Handler A, Pace R, Zou F, Zariwala M, Fargo D, Xu A, Dunn JM, et al.: Genetic modifiers of lung disease in cystic fibrosis. $N$ Engl J Med 2005, 353( I 4): | 443- | 453.

90. Wilmott RW, Tyson SL, Dinwiddie R, Matthew DJ: Survival rates in cystic fibrosis. Arch Dis Child 1983, 58(1 0):835-836.

91. Kerem E, Corey M, Gold R, Levison H: Pulmonary function and clinical course in patients with cystic fibrosis after pulmonary colonization with Pseudomonas aeruginosa. J Pediatr 1990, I | 6(5):7|4-7|9.

Publish with Bio Med Central and every scientist can read your work free of charge

"BioMed Central will be the most significant development for disseminating the results of biomedical research in our lifetime. "

Sir Paul Nurse, Cancer Research UK

Your research papers will be:

- available free of charge to the entire biomedical community

- peer reviewed and published immediately upon acceptance

- cited in PubMed and archived on PubMed Central

- yours - you keep the copyright
BioMedcentral 